\title{
BMJ Open Prevalence and associated factors of facial palsy and lifestyle characteristics: data from the Korean National Health and Nutrition Examination Survey 2010-2012
}

\author{
Young-Soo Chang, ${ }^{1}$ Ji Eun Choi, ${ }^{1}$ Seon Woo Kim, ${ }^{2}$ Sun-Young Baek, ${ }^{2}$ \\ Yang-Sun $\mathrm{Cho}^{1}$
}

To cite: Chang Y-S, Choi JE, Kim SW, et al. Prevalence and associated factors of facial palsy and lifestyle characteristics: data from the Korean National Health and Nutrition Examination Survey 2010-2012. BMJ Open 2016;6: 012628.

doi:10.1136/bmjopen-2016012628

- Prepublication history for this paper is available online. To view these files please visit the journal online (http://dx.doi.org/10.1136/ bmjopen-2016-012628).

Received 13 May 2016 Revised 10 October 2016 Accepted 13 October 2016

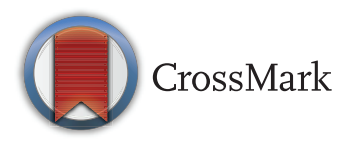

${ }^{1}$ Department of Otorhinolaryngology-Head and Neck Surgery, Samsung Medical Center,

Sunkyunkwan University School of Medicine, Seoul, Korea

${ }^{2}$ Biostatistics and Clinical Epidemiology Center, Research Institute for Future Medicine, Samsung Medical Center, Sunkyunkwan University School of Medicine, Seoul, Korea

Correspondence to Professor Yang-Sun Cho; yscho@skku.edu

\section{ABSTRACT}

Objectives: To report the nationwide prevalence of facial palsy (FP) of grade III or worse in the HouseBrackmann (H-B) grading system in South Korea and assess the associated factors.

Design: Cross-sectional analysis of a nationwide health survey.

Settings: South Korea.

Methods: We obtained data from the 2010 to 2012 Korea National Health and Nutrition Examination Surveys, which were cross-sectional surveys of the South Korean civilian population living in households and aged $\geq 1$ year ( $N=23533$ ). A field survey team performed interviews, physical examinations and laboratory tests. Facial expression was evaluated based on the $\mathrm{H}-\mathrm{B}$ grading system.

Results: Among the population aged $\geq 1$ year, the prevalence of FP of grade III or worse in the $\mathrm{H}-\mathrm{B}$ grading system was $0.12 \%(95 \% \mathrm{Cl} 0.07 \%$ to $0.17 \%)$. FP was more prevalent in women $(p=0.01)$ and the prevalence rate increased with age $(p<0.001)$. In participants aged $\geq 19$ years, age, female gender, history of cardiovascular disease and the serum total cholesterol level were associated with FP in a multivariable analysis. In the evaluation of lifestyle, the individuals with FP had a higher rate of depressive mood and were more restricted in their daily activities.

Conclusions: Considering the significance of facial expression in psychosocial activities, public acknowledgement and further intervention are required to support patients with this distressing condition.

\section{INTRODUCTION}

The face plays a major role during interpersonal communication, and facial expression is of interest from both an evolutionary ${ }^{1}$ and a social standpoint. ${ }^{2}$ A critical facial expression is produced by the contraction and coordination of the facial muscles, and this is mainly innervated by the facial nerve. When the function of the facial nerve is disturbed,

\section{Strengths and limitations of this study}

- This is the first nationwide survey to elucidate the prevalence and associated factors of facial palsy (FP) of grade III or worse in the HouseBrackmann (H-B) grading system.

- The population of patients with FP of grade III or worse $(0.12 \%$ of this survey) was compared with the participants without FP $(99.88 \%$ of this survey) and sample weights were applied in all analyses to reflect national population estimates.

- Multivariable analysis with the logistic regression model was applied to elucidate the factors associated with FP.

- A limitation of our study is that some potentially associated factors were not available in the evaluation, similar to other large-scale crosssectional surveys.

significant changes may occur, with impaired facial expression. Abnormal facial movement and diminished facial expression can pose challenges in face-to-face communications. ${ }^{3}$ Bell's palsy, herpes zoster oticus, trauma, surgical removal of vestibular schwannoma and iatrogenic damage of the facial nerve are common conditions that restrict facial expression. ${ }^{4}$ The incidence of the five major aetiologies in the $\mathrm{USA}^{5}$ is as follows: Bell's palsy ( 25 cases per 100000 annually), ${ }^{6}$ infection including herpes zoster oticus, Lyme disease and otitis media $(7.7$ cases per 100000 annually), ${ }^{7-9}$ neoplastic aetiologies (6.8 cases per 100000 annually), ${ }^{7}$ neurologic aetiologies including cerebrovascular accidents (6.8 cases per 100000 annually) ${ }^{8} 10$ and traumatic aetiologies (4.1 cases per 100000 annually). ${ }^{11} 12$

Several previous studies have been conducted to evaluate this clinical implication of 
facial palsy (FP). ${ }^{13-15}$ Leong and Lesser used the Facial Clinimetric Evaluation (FaCE) Scale to evaluate the effect of FP on the quality of life (QoL) of patients with vestibular schwannoma. ${ }^{15}$ They suggested that centres dedicated to the management of vestibular schwannoma should offer facial nerve rehabilitation as part of the services they provide.

Although estimated incidences of disorders that cause FP have been reported ${ }^{5}$ and the significance of FP on QoL in each individual is well noted, the exact prevalence of FP in the general population has not been reported.

Nationwide epidemiological studies that are conducted by a government organisation can provide powerful data for investigating the national prevalence of diseases. ${ }^{16}$ The Korea National Health and Nutrition Examination Survey (KNHANES) assesses the general health and nutritional status of populations in South Korea using interviews on their health and nutrition, and a basic health assessment of the participants.

We aimed to evaluate the prevalence of FP of grade III or worse in the House-Brackmann (H-B) grading system in South Korea based on survey data obtained from the 2010-2012 KNHANES and to investigate associated factors. In addition, we assessed the lifestyle characteristics of individuals with FP.

\section{METHODS}

\section{Participants}

The KNHANES is a nationwide survey that is conducted annually by the Korea Centers for Disease Control and Prevention to investigate the health and nutritional status of a representative Korean population. This survey is an ongoing cross-sectional survey of the civilian population living in households aged $\geq 1$ year of South Korea and described in elsewhere. ${ }^{16-18}$ A field survey team that included an otolaryngologist, an ophthalmologist and nurse examination unit performed interviews and physical examinations. Individuals selected underwent a basic health assessment that included blood pressure measurements, blood and urine collection, pulmonary function test and dental examination, ophthalmologic examination and otolaryngological examination. A history of otological symptoms was surveyed and physical examination, including the tympanic membrane, hearing and balance, was conducted in participants of appropriate ages. Every year 10000-12000 people in about 3800 households are selected from a panel to represent the population using a multistage clustered and stratified random sampling method that is based on the National Census Data. One hundred and ninety-two survey sections were randomly sampled and 20 households were selected from each section. ${ }^{19}$ The participation rate of selected households in the past several cycles of KNHANES has been high, ranging from $79 \%$ to $84 \%$. By using the sample weight, this survey provides representative estimates of the Korean civilian population living in households.
Written informed consent was obtained from all the participants before the survey, and approval for this research was obtained from the institutional review board of the Samsung Medical Center (IRB No. 2013-02-031).

\section{Evaluation of facial expression}

In this survey, the facial expression analysis was based on the $\mathrm{H}-\mathrm{B}$ grading system, which is adopted by the American Academy of Otolaryngology-Head and Neck Surgery. ${ }^{20}$ In this system, grades I and II are normal to near-normal, whereas grades III or worse are a status which has definite asymmetry. Therefore, the facial expression of participants was evaluated and categorised as grades I-II and III-VI by a trained otolaryngologist, and those who had grades III-VI were recorded as having FP.

\section{Evaluation of associated factors}

Potentially associated factors from the basic health examination, interview and laboratory tests were evaluated for their association with FP. Age, gender, smoking status (non-smoker/ex-smoker or current smoker) and alcohol drinking (less than one a month/more than one a month) were collected. A history of hypertension (yes/ no), hyperlipidaemia (yes/no), stroke (yes/no), cardiovascular diseases (CVD) (yes/no), diabetes mellitus (yes/no), which had been diagnosed by physicians, was also collected. In laboratory tests, total cholesterol level $(\mathrm{mg} / \mathrm{dL})$, high-density lipoprotein-cholesterol and the white blood cell count (total cell $\times 10^{3}$ counts $/ \mu \mathrm{L}$ ) were evaluated.

\section{Otological examination and audiometric measurement}

An ear examination was conducted with a $4 \mathrm{~mm} 0^{\circ}$ angled rigid endoscope attached to a charge-coupled device camera for all participants to find tympanic membrane perforation and cholesteatoma.

The pure tone air-conduction threshold was obtained in a soundproof booth using an automatic audiometer (GSI SA-203, Entomed Diagnostics AB, Lena Nodin, Sweden). Hearing loss was defined as $\geq 25 \mathrm{~dB}$ loss, on average, of air-conduction hearing thresholds at $0.5,1,2$ and $3 \mathrm{kHz} .^{21}$ Balance function was evaluated by asking subjects about positional vertigo and history of any balance problems.

\section{Evaluation of lifestyle characteristics}

The following lifestyle characteristics of patients with FP were assessed with self-reporting questionnaires: QoL (evaluated by EQ-5D score from the EuroQol group ${ }^{22}$ ), frequency of depressive mood lasting for $\geq 2$ weeks (yes/ no), experience of depressive mood and recognition of stress (yes/no), self-reporting subjective feeling about general health (good/fair/poor), hindrance of daily activities (no, some trouble, not able to carry out daily activities) and status of economic activities (employed/ unemployed). 


\section{Statistical analysis}

The participants without FP (99.88\% of this survey) were used as a control group to evaluate the factors associated with the participants with FP $(0.12 \%$ of this survey). The sample weight was adjusted during the statistical analysis. Potentially associated factors were evaluated by univariable analysis. The prevalence and 95\% CIs were calculated. In univariable analysis, logistic regression analysis (using PROC SURVEYLOGISTIC in SAS V.9.3; SAS Institute, Cary, North Carolina, USA) was used to test the association between FP and associated factors in a complex sampling design. Only variables with a $\mathrm{p}$ value $\leq 0.20$ were selected for multivariable analysis with the logistic regression model. To evaluate the association between FP and potentially associated factors, adjusted ORs with 95\% CIs were calculated using logistic regression analysis (using PROC SURVEYLOGISTIC in SAS).

Evaluation of lifestyle characteristics of patients with FP was performed including hearing loss as a possible confounding factor (using PROC SURVEYREG, PROC SURVEYLOGISTIC in SAS).

To reflect national population estimates, sample weights were applied in all analyses. All $\mathrm{p}$ values were two-sided, and $\mathrm{p}<0.05$ was considered to be statistically significant.

\section{RESULTS}

\section{Prevalence of FP}

A total of 23621 individuals aged $\geq 1$ year participated in the survey between 2010 and 2012. Among them, 23533 were evaluated for facial expression; the prevalence of
FP of $\mathrm{H}-\mathrm{B}$ grade III or worse was $0.12 \%$ (95\% CI $0.07 \%$ to $0.17 \%$ ). Of the participants, 10576 were male and 12957 female, and weighted sum was a population of 47656438 . The prevalence of FP increased with age $(\mathrm{p}<0.001)$. The prevalence of FP in men and women was 0.07 and 0.17 , respectively, and men had a significantly lower prevalence than women $(\mathrm{p}=0.01)$ (table 1$)$. No difference in the laterality of FP was found $(\mathrm{p}=0.73)$ (table 1).

\section{Analysis of associated factors}

As the questionnaire survey and otological examination were available for participants aged $\geq 19$ years $(\mathrm{n}=17988)$, an association analysis was performed in this population. A total of 14394 participants completed all the questionnaires and physical examination. The prevalence and significance of associated factors, including data from the questionnaire, laboratory tests and the otolaryngological survey and examinations in the study population, are presented in table 2. FP and associated factors were investigated using univariable and multivariable analyses. In the univariable analysis, FP was associated with age, gender, smoking status, alcohol drinking, history of hypertension, stroke, CVD, diabetes mellitus, total cholesterol level in the blood and hearing loss.

After multivariable-adjusted analysis, older age $(\mathrm{OR}=1.05,95 \%$ CI 1.01 to 1.09$)$, gender $(\mathrm{OR}=0.17,95 \%$ CI 0.03 to 0.93 ), history of CVD (OR=4.01, 95\% CI 1.02 to 15.71) and serum total cholesterol level (OR=1.01, $95 \%$ CI 1.00 to 1.03 ) remained as factors associated with FP (table 2).

Table 1 Prevalence of facial palsy by gender and age group in participants aged $>1$ year $(n=23533)$

\begin{tabular}{|c|c|c|c|c|c|c|}
\hline \multirow[b]{2}{*}{ Characteristics } & \multirow[b]{2}{*}{ Frequency } & \multirow[b]{2}{*}{ Weighted frequency } & \multicolumn{4}{|c|}{ Facial palsy } \\
\hline & & & $\mathbf{n}$ & Per cent* & $95 \% \mathrm{Cl}$ & p Value \\
\hline Gender & 23533 & 47656438 & 44 & 0.12 & 0.07 to 0.17 & \\
\hline Male & 10576 & 23832885 & 16 & 0.07 & 0.03 to 0.12 & $0.01 \dagger$ \\
\hline Female & 12957 & 23823553 & 28 & 0.17 & 0.09 to 0.25 & \\
\hline Side & 23533 & 47656438 & 44 & 0.12 & 0.07 to 0.17 & \\
\hline Right & & & 25 & 0.06 & 0.03 to 0.09 & 0.73 \\
\hline Left & & & 19 & 0.06 & 0.03 to 0.09 & \\
\hline \multicolumn{7}{|l|}{ Age (years) } \\
\hline Total $(\geq 1)$ & 23533 & 47656438 & 44 & 0.12 & 0.07 to 0.17 & $<0.001 \ddagger$ \\
\hline $1-9$ & 2873 & 4182333 & 0 & 0 & 0 & \\
\hline $10-19$ & 2860 & 6437853 & 0 & 0 & 0 & \\
\hline $20-29$ & 1861 & 6556479 & 0 & 0 & 0 & \\
\hline $30-39$ & 3284 & 7772849 & 1 & 0.03 & 0 to 0.08 & \\
\hline $40-49$ & 3174 & 8141849 & 2 & 0.04 & 0 to 0.09 & \\
\hline $50-59$ & 3425 & 6830269 & 9 & 0.21 & 0.05 to 0.36 & \\
\hline $60-69$ & 3084 & 4037451 & 15 & 0.43 & 0.12 to 0.73 & \\
\hline $70-79$ & 2422 & 2901000 & 16 & 0.68 & 0.26 to 1.09 & \\
\hline $80-89$ & 536 & 779026 & 1 & 0.21 & 0 to 0.63 & \\
\hline$>90$ & 14 & 17329 & 0 & 0 & 0 & \\
\hline
\end{tabular}




\begin{tabular}{|c|c|c|c|c|c|c|c|c|}
\hline \multirow[b]{2}{*}{ Variables } & \multirow[b]{2}{*}{ Per cent ${ }^{*}$} & \multirow[b]{2}{*}{ Prevalence } & \multicolumn{3}{|c|}{ Univariable analysis } & \multicolumn{3}{|c|}{ Multivariable analysis } \\
\hline & & & p Value & OR & $95 \% \mathrm{Cl}$ & p Value & OR & $95 \% \mathrm{Cl}$ \\
\hline Age & & 0.09 & $<0.001$ & 1.08 & 1.04 to 1.12 & 0.02 & 1.05 & 1.01 to 1.09 \\
\hline \multicolumn{9}{|l|}{ Gender } \\
\hline Female & 75 & 0.15 & & Referent & & & Referent & \\
\hline Male & 25 & 0.02 & 0.002 & 0.13 & 0.04 to 0.46 & 0.04 & 0.17 & 0.03 to 0.93 \\
\hline \multicolumn{9}{|l|}{ Data obtained from the questionnaire } \\
\hline \multicolumn{9}{|l|}{ Smoking, current } \\
\hline No & 70 & 0.13 & & Referent & & & Referent & \\
\hline Yes & 30 & 0.04 & 0.04 & 0.28 & 0.08 to 0.94 & 0.68 & 1.39 & 0.29 to 6.73 \\
\hline \multicolumn{9}{|l|}{ Alcohol drinking } \\
\hline No & 65 & 0.17 & & Referent & & & Referent & \\
\hline Yes & 35 & 0.03 & 0.002 & 0.19 & 0.07 to 0.55 & 0.27 & 0.51 & 0.15 to 1.69 \\
\hline \multicolumn{9}{|l|}{ History of hypertension } \\
\hline No & 60 & 0.06 & & Referent & & & Referent & \\
\hline Yes & 40 & 0.24 & 0.01 & 4.23 & 1.39 to 12.86 & 0.81 & 1.16 & 0.36 to 3.73 \\
\hline \multicolumn{9}{|l|}{ History of hyperlipidaemia } \\
\hline No & 85 & 0.08 & & Referent & & & & \\
\hline Yes & 15 & 0.10 & 0.81 & 1.12 & 0.30 to 4.67 & & & \\
\hline \multicolumn{9}{|l|}{ History of stroke } \\
\hline No & 90 & 0.08 & & Referent & & & Referent & \\
\hline Yes & 10 & 0.71 & 0.03 & 9.12 & 1.28 to 65.21 & 0.22 & 4.40 & 0.42 to 45.97 \\
\hline \multicolumn{9}{|l|}{ History of CVD } \\
\hline No & 75 & 0.08 & & Referent & & & Referent & \\
\hline Yes & 25 & 0.71 & $<0.001$ & 5.66 & 2.23 to 14.35 & 0.04 & 4.01 & 1.02 to 15.71 \\
\hline \multicolumn{9}{|l|}{ History of DM } \\
\hline No & 80 & 0.07 & & Referent & & & Referent & \\
\hline Yes & 20 & 0.36 & 0.03 & 5.18 & 1.18 to 22.70 & 0.21 & 2.64 & 0.57 to 12.17 \\
\hline \multicolumn{9}{|l|}{ Laboratory data } \\
\hline Total cholesterol level (mg/dL) (mean) & & 0.09 & 0.01 & 1.01 & 1.00 to 1.03 & 0.04 & 1.01 & 1.00 to 1.03 \\
\hline HDL-C (mean) & & 0.09 & 0.98 & 1.00 & 0.94 to 1.07 & & & \\
\hline \multicolumn{9}{|l|}{ WBC count } \\
\hline$<6.0 \times 10^{3} / \mu \mathrm{L}$ & 65 & 0.12 & & Referent & & & Referent & \\
\hline$\geq 6.0 \times 10^{3} / \mu \mathrm{L}$ & 35 & 0.05 & 0.13 & 0.42 & 0.13 to 1.31 & 0.15 & 0.39 & 0.11 to 1.38 \\
\hline \multicolumn{9}{|l|}{ Otological examination } \\
\hline \multicolumn{9}{|l|}{ TM perforation } \\
\hline No & 100 & 0.09 & & & & & & \\
\hline Yes & 0 & 0 & & & & & & \\
\hline \multicolumn{9}{|l|}{ Cholesteatoma } \\
\hline No & 95 & 0.08 & & Referent & & & Referent & \\
\hline Yes & 5 & 0.33 & 0.18 & 4.00 & 0.53 to 30.18 & 0.43 & 2.3 & 0.30 to 17.91 \\
\hline
\end{tabular}




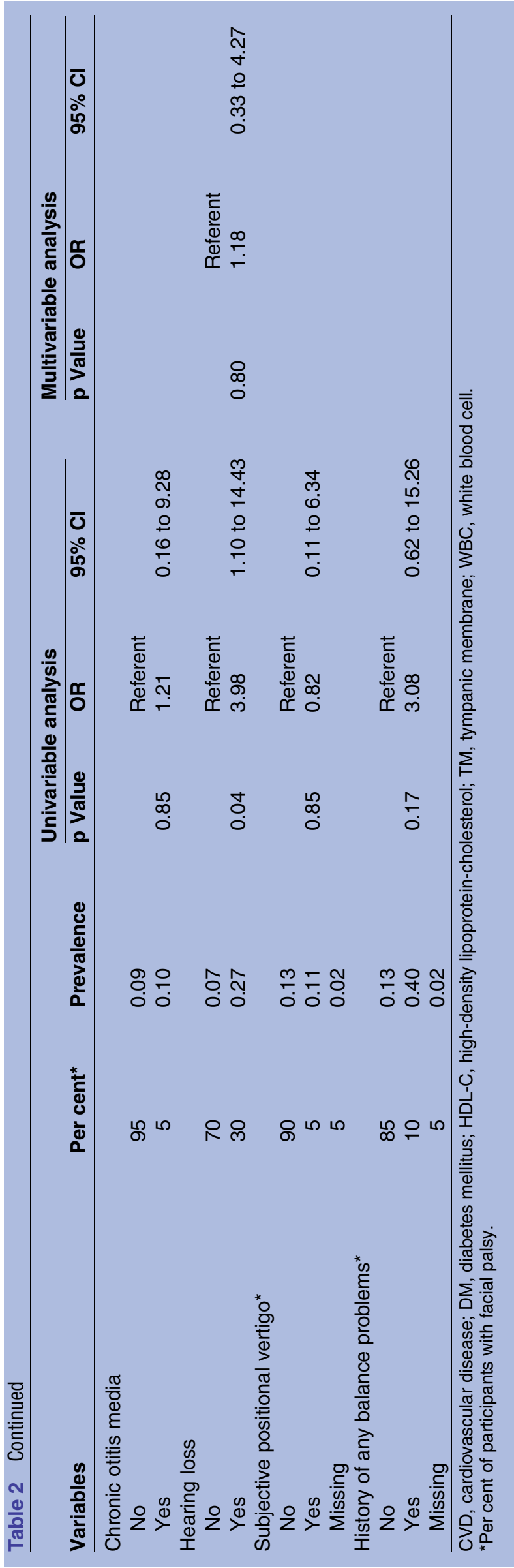

Analysis of lifestyle characteristics

QoL, assessed with EQ-5D did not show a difference between normal participants and individuals with FP $(\mathrm{p}=0.11)$ (table 3$)$. However, the prevalence of a history of depressive mood for $\geq 2$ weeks was greater $(31.96 \%)$ in participants with $\mathrm{FP}(\mathrm{p}=0.03, \mathrm{OR}=2.76$; $95 \%$ CI 1.09 to 7.03 ). Hindrance of daily activities was surveyed and $4.76 \%$ of individuals with $\mathrm{FP}$ reported that they were unable to perform usual daily activities. Those individuals had a high OR for restriction of daily activities compared with normal participants $(\mathrm{p}=0.01, \mathrm{OR}=3.38$; $95 \%$ CI 1.33 to 8.59 ).

\section{DISCUSSION}

This survey provides the prevalence rate of FP and also an interesting perspective on associated factors and the impact on patients' daily life using the data from the nationwide survey. Nevertheless, several important considerations warrant attention when assessing the results of this survey. First, because this was a large-scale crosssectional survey, some variables were not available and were not fully elucidated, similar to other cross-sectional studies. In addition, the survey did not fully evaluate the duration and aetiology of FP in each participant. Second, although one of the aims of this study was to elucidate the associated factors and the general characteristics in daily life, a low prevalence of FP can be a limiting factor to demonstrate potentially associated factors. However, as this survey adapted sample weights in all analyses, the statistical power in this survey was sufficient.

The prevalence of FP of $\mathrm{H}-\mathrm{B}$ grade III or worse was $0.12 \%$ in our survey. This is the first epidemiological study to demonstrate the nationwide prevalence of FP, regardless of the aetiology, with a government-centred survey. Facial expression has a key role in face-to-face communications. ${ }^{3}$ An impaired facial movement alters the way in which an individual is perceived by, and interacts with, others. Therefore, FP is a significant healthcare problem and clarification of its prevalence has important clinical implications.

Analysis showed that age and gender were significantly associated with FP. FP is one of the consequences of various diseases, and the number of patients with incomplete recovery is cumulative and increases with ageing. Furthermore, age is an important factor resulting in incomplete recovery from Bell's palsy. ${ }^{23}$

In our study, a history of CVD had a strong association with $\mathrm{FP}(\mathrm{OR}=4.01,95 \%$ CI 1.02 to 15.71$)$. This finding is consistent with previous reports stating that neurologic aetiologies, including cerebrovascular accidents, are a major cause of FP. In addition, it is reported that the risk of incomplete recovery from FP is greater in cerebral palsy than in Bell's palsy. ${ }^{24}$ The serum total cholesterol level, which is well-known risk factor for CVD also had a significant association with FP in our study $(\mathrm{OR}=1.01,95 \%$ CI 1.00 to 1.03$) .^{25-28}$ 
Table 3 Lifestyle characteristics of participants with facial paralysis

\begin{tabular}{|c|c|c|c|c|c|c|c|}
\hline \multirow[b]{2}{*}{ Characteristics } & \multicolumn{2}{|c|}{ Facial paralysis } & \multicolumn{2}{|l|}{ Control } & \multirow[b]{2}{*}{ p Value } & \multirow[b]{2}{*}{ OR } & \multirow[b]{2}{*}{$95 \% \mathrm{Cl}$} \\
\hline & n (\%) & $\begin{array}{l}\text { Weighted } \\
\text { frequency }\end{array}$ & n (\%) & $\begin{array}{l}\text { Weighted } \\
\text { frequency }\end{array}$ & & & \\
\hline \multirow{2}{*}{\multicolumn{5}{|c|}{$\begin{array}{l}\text { Quality of life score }(E Q-5 D)^{*} \\
\text { Frequency of depressive mood lasting for } \geq 2 \text { weeks } \dagger\end{array}$}} & 0.11 & & \\
\hline & & & & & & & \\
\hline No & $25(68.04)$ & 28942 & $13650(87.27)$ & 28952251 & & Referent & \\
\hline Yes & 9 (31.96) & 13595 & 2046 (12.73) & 4221648 & 0.03 & 2.76 & 1.09 to 7.03 \\
\hline \multicolumn{8}{|c|}{ Experience of depressive mood and recognition of stress $\dagger$} \\
\hline No & $24(61.39)$ & 26115 & $11571(72.44)$ & 24029752 & & Referent & \\
\hline Yes & $10(38.61)$ & 16421 & $4125(27.56)$ & 9144146 & 0.31 & 1.61 & 0.64 to 4.08 \\
\hline \multicolumn{8}{|c|}{ Self-reporting subjective feeling about general health $\ddagger$} \\
\hline Good & $9(33.97)$ & 14450 & $5271(34.93)$ & 11588582 & 0.75 & 1.14 & 0.51 to 2.51 \\
\hline Fair & $17(45.51)$ & 19357 & $7685(48.20)$ & 15988252 & & & \\
\hline Poor & $8(20.52)$ & 8729 & $2941(16.87)$ & 5597064 & & & \\
\hline \multicolumn{8}{|c|}{ Hindrance of daily activities $\ddagger$} \\
\hline & & & & & 0.01 & 3.38 & 1.33 to 8.59 \\
\hline No & $26(77.30)$ & 32882 & 14561 (92.92) & 30912573 & & & \\
\hline Some trouble & $6(17.94)$ & 7631 & $1362(6.31)$ & 2032713 & & & \\
\hline $\begin{array}{l}\text { Not able to carry out } \\
\text { daily activities }\end{array}$ & $2(4.76)$ & 2204 & $164(0.77)$ & 228611 & & & \\
\hline \multicolumn{8}{|c|}{ Status of economic activities $\dagger$} \\
\hline Employed & $18(59.59)$ & 25346 & $9646(65.32)$ & 21668878 & & Referent & \\
\hline Unemployed & $15(40.41)$ & 17190 & $6441(34.68)$ & 11505020 & 0.69 & 1.12 & 0.53 to 2.64 \\
\hline
\end{tabular}

We evaluated the lifestyle characteristics of individuals with FP. The presence of hearing loss, which often accompanies FP was accounted for as a confounding factor. Compared with the normal population, those with FP had a frequent history of depressive mood for $\geq 2$ weeks and a higher rate of hindrance in carrying out daily activities. Although QoL assessed with EQ-5D showed no difference between those with FP and normal participants, our result reflects the poor lifestyle characteristics of individuals with FP, in accordance with previous studies. ${ }^{29-31}$ In this analysis, we could not account for every possible confounding factor, such as the duration and aetiology of FP, or other comorbidities. This might have impeded a demonstration of detailed lifestyle characteristics in participants with FP.

In summary, the overall prevalence of $\mathrm{FP}$ of $\mathrm{H}-\mathrm{B}$ grade III or worse is $0.12 \%$ in the general population of South Korea. This condition is more prevalent in women, those who are older, those with a history of CVD and higher serum total cholesterol level. Individuals with FP had the higher rate of depressive mood and greater restriction of daily activities. Although FP is rare, public acknowledgement and parallel intervention to modify the associated factors are required to support patients with this distressing condition.

Acknowledgements We thank the 150 residents of the otorhinolaryngology departments of 47 training hospitals in South Korea and members of the Division of Chronic Disease Surveillance in Korea Centers for Disease Control and Prevention for participating in this survey and their dedicated work.
Contributors Young-SC and Yang-SC designed the study. Young-SC, JEC, SWK and S-YB analyzed the information on the Korean National Health and Nutrition Examination Survey 2010-2012. Young-SC wrote the first draft of the paper. All authors were involved in interpreting the data and revising the first draft. All authors approved the final draft of the manuscript.

Funding This research received no specific grant from any funding agency in the public, commercial or not-for-profit sectors.

Competing interests None declared.

Patient consent Obtained.

Ethics approval Institutional review board of the Samsung Medical Center (IRB No. 2013-02-031).

Provenance and peer review Not commissioned; externally peer reviewed.

Data sharing statement No additional data are available.

Open Access This is an Open Access article distributed in accordance with the Creative Commons Attribution Non Commercial (CC BY-NC 4.0) license, which permits others to distribute, remix, adapt, build upon this work noncommercially, and license their derivative works on different terms, provided the original work is properly cited and the use is non-commercial. See: http:// creativecommons.org/licenses/by-nc/4.0/

\section{REFERENCES}

1. Darwin C, Ekman $\mathrm{P}$, Prodger P. The expression of the emotions in man and animals. New York: Oxford University Press, 1998.

2. McGrouther DA. Facial disfigurement. BMJ 1997;314:991.

3. Bradbury ET, Simons W, Sanders R. Psychological and social factors in reconstructive surgery for hemi-facial palsy. J Plast Reconstr Aesthet Surg 2006;59:272-8.

4. Kahn JB, Gliklich RE, Boyev KP, et al. Validation of a patient-graded instrument for facial nerve paralysis: the FaCE scale. Laryngoscope 2001;111:387-98.

5. Bleicher JN, Hamiel S, Gengler JS, et al. A survey of facial paralysis: etiology and incidence. Ear Nose Throat J 1996;75:355-8. 
6. Katusic SK, Beard CM, Wiederholt WC, et al. Incidence, clinical features, and prognosis in Bell's palsy, Rochester, Minnesota, 1968-1982. Ann Neurol 1986;20:622-7.

7. Moore GF. Facial nerve paralysis. Prim Care 1990;17:437-60.

8. Ratanaprasatporn S, Rizza A, Lapidot A. Facial nerve palsy: five year survey. J Laryngol Otol 1972;86:155-9.

9. Dennis DT. Lyme disease. Tracking an epidemic. JAMA 1991;266:1269-70.

10. May M. Facial paralysis, peripheral type: a proposed method of reporting. (Emphasis on diagnosis and prognosis, as well as electrical and chorda tympani nerve testing). Laryngoscope 1970;80:331-90.

11. Kamerer DB. Intratemporal facial nerve injuries. Otolaryngol Head Neck Surg 1982;90:612-15.

12. Cannon CR, Jahrsdoerfer RA. Temporal bone fractures. Review of 90 cases. Arch Otolaryngol 1983;109:285-8.

13. Ho AL, Scott AM, Klassen AF, et al. Measuring quality of life and patient satisfaction in facial paralysis patients: a systematic review of patient-reported outcome measures. Plast Reconstr Surg 2012;130:91-9.

14. Coulson SE, O'Dwyer NJ, Adams RD, et al. Expression of emotion and quality of life after facial nerve paralysis. Otol Neurotol 2004;25:1014-19.

15. Leong SC, Lesser TH. A national survey of facial paralysis on the quality of life of patients with acoustic neuroma. Otol Neurotol 2015;36:503-9.

16. Park KH, Lee $\mathrm{SH}, \mathrm{Koo} \mathrm{J}-\mathrm{W}$, et al. Prevalence and associated factors of tinnitus: data from the Korean National Health and Nutrition Examination Survey 2009-2011. J Epidemiol 2014;24: 417

17. Cho YS, Choi SH, Park KH, et al. Prevalence of otolaryngologic diseases in South Korea: data from the Korea National Health and Nutrition Examination Survey 2008. Clin Exp Otorhinolaryngol 2010;3:183-93.

18. Kang JW, Choi HS, Kim K, et al. Dietary vitamin intake correlates with hearing thresholds in the older population: the Korean National Health and Nutrition Examination Survey. Am J Clin Nutr 2014;99:1407-13.
19. Kweon S, Kim Y, Jang MJ, et al. Data resource profile: the Korea National Health and Nutrition Examination Survey (KNHANES) Int J Epidemiol 2014;43:69-77.

20. House JW, Brackmann DE. Facial nerve grading system. Otolaryngol Head Neck Surg 1985;93:146-7.

21. Committee on Hearing and Equilibrium guidelines for the evaluation of results of treatment of conductive hearing loss. American Academy of Otolaryngology-Head and Neck Surgery Foundation Inc. Otolaryngol Head Neck Surg 1995;113:186-7.

22. Hurst NP, Kind P, Ruta D, et al. Measuring health-related quality of life in rheumatoid arthritis: validity, responsiveness and reliability of EuroQol (EQ-5D). Br J Rheumatol 1997;36:551-9.

23. Peitersen E. Bell's palsy: the spontaneous course of 2,500 peripheral facial nerve palsies of different etiologies. Acta Otolaryngol Supp/ 2002;549:4-30.

24. Cha Cl, Hong CK, Park MS, et al. Comparison of facial nerve paralysis in adults and children. Yonsei Med J 2008;49:725-34

25. Lind L, Lithell H. Decreased peripheral blood flow in the pathogenesis of the metabolic syndrome comprising hypertension, hyperlipidemia, and hyperinsulinemia. Am Heart $J$ 1993;125:1494-7.

26. Yang Y, Li JX, Chen JC, et al. Effect of elevated total cholesterol level and hypertension on the risk of fatal cardiovascular disease: a cohort study of Chinese steelworkers. Chin Med J (Engl) 2011;124:3702-6.

27. Nagasawa SY, Okamura T, Iso $\mathrm{H}$, et al. Relation between serum total cholesterol level and cardiovascular disease stratified by sex and age group: a pooled analysis of 65594 individuals from 10 cohort studies in Japan. J Am Heart Assoc 2012;1:e001974.

28. Verschuren WM, Jacobs DR, Bloemberg BP, et al. Serum total cholesterol and long-term coronary heart disease mortality in different cultures. Twenty-five-year follow-up of the seven countries study. JAMA 1995;274:131-6.

29. Bradbury ET, Simons W, Sanders R. Psychological and social factors in reconstructive surgery for hemi-facial palsy. J Plast Reconstr Aesthet Surg 2006;59:272-8.

30. Fu L, Bundy C, Sadiq SA. Psychological distress in people with disfigurement from facial palsy. Eye (Lond) 2011;25:1322-6.

31. Weir A, Pentland B, Crosswaite A, et al. Bell's palsy: the effect on self-image, mood state and social activity. Clin Rehabil 1995;9:121-5. 